\title{
Student Outcomes (Primary, Secondary and Higher Education)
}

\author{
Lane Perry \\ Tami Moore \\ Billy O'Steen
}

This article was originally published at:

https://journals.sfu.ca/iarslce/index.php/journal/article/view/259/170

Recommended Citation

Perry, L., Moore, T., \& O'Steen, B. (2016). Student outcomes (primary, secondary and higher education). International Journal of Research on Service-Learning and Community Engagement, 4(1), 213-215. 


\title{
Student Outcomes (Primary, Secondary and Higher Education)
}

\author{
Lane Perry \\ Tami Moore \\ Billy O'Steen
}

\author{
Section Co-Editors
}

The rich literature of the civic engagement and service-learning movement provides well-established findings about student outcomes. Even so, many questions remain, including

theory-driven questions about [the nature or extent of these] outcomes, about the contribution of service-learning and community engagement in addition or in contrast to other active-learning methods, about the role of contextual variables, and about the effects of specific types of servicelearning and community engagement on students. (Perry \& Osteen, 2015, p. 1)

Fortunately, the Student Outcomes section of the 2016 volume of IJRSLCE is supported by an abundance of submissions that provide insight into either previously untapped outcomes or approaches that help learners reach empirically established outcomes. Each article in the section is summarized briefly here.

In "Fostering Undergraduate Spiritual Growth Through Service-Learning," Sterk Barrett discusses a study for which she adopted a mixed-methods approach incorporating two distinct phases. Phase One used the College Students' Beliefs and Values survey (Astin, Astin, \& Lindholm, 2011) to inform an emergent spiritual orientation scale (SOS) administered as a pre/post-service survey, while Phase Two sought to deepen and expand the findings associated with the SOS through semi-structured interviews. Analysis of the relationship between service-learning components and spiritual growth suggested that spiritual growth occurred when students experienced significant challenge balanced by intentional support.

In their research article "Pre-College Factors Influencing College Students' Civic Attitudes: The Importance of Familial and Community Service Experiences," Moely and Illustre replicate and extend an investigation of contributors to first-year university students' attitudes toward a graduation service requirement and civic attitudes, such as civic responsibility and attitudes toward social justice. Results showed that family orientation toward service and pre-college service experience predicted attitudes toward the service requirement and civic attitudes, while pre-college service experience had a mediating effect on family orientation toward service

In their research-outlined in "'I just kept quiet': Exploring Equity in a Service-Learning Programme"-Bheekie, van Hussteen, Rae, and Swartbooi applied a discomfort theory framework to examine the responses of pharmacy students in Cape Town, South Africa, to incidents of social injustice in health care facilities that served as their service-learning placement venues. Results of qualitative analyses showed that students' habitual response to incidents of discrimination by colleagues, doctors, and patients were silence and inaction induced by fear of speaking out, an emotion perpetuated by power dynamics within the status quo. Upon reflecting on their responses, students were dissatisfied with their passivity in the face of discrimination by colleagues and doctors, and felt that promoting equality of healthcare and educating colleagues were professional responsibilities. 
In the research article, "University Community Engagement and Public Relations Education: A Replication and Extension of Service-Learning Assessment in the PR Campaigns Course," Farmer, Perry, and Ha discuss how they retested and extended Werder and Strand's 2011 assessment of the impact of service-learning on students in a PR Campaigns course to include alumni as participants and outcomes beyond those specific to the course, such as citizenship and social responsibility. Extensive findings resulted from the quantitative and qualitative data analyses. For example, service-learning yielded perceived impacts on four general areas of learning, including communications and application skills, and on three categories of discipline-specific learning, such as organizational and technical skills. Both perceived general and discipline-specific learning gains predicted students' overall assessment of the effectiveness of the course, with technical skills emerging as the strongest predictor.

Stanlick and Hammond adopted Chickering's $(1964,1993)$ framework of postsecondary adolescent development and Winne and Hadwin's (1998) model of self-regulated learning to examine the influence of a short-term international service-learning experience, particularly the reflection component, on 10 students' development. Using qualitative data from several types of reflection activities and the results of quantitative pre/posttest surveys, the authors were able to construct profiles of the development and relationships between ambiguity tolerance, ethno-cultural empathy, and motivation for each participant.

While these articles help to advance the collective work of the field of service-learning and community engagement, there is still explicit and implicit need for research that is well developed. Early on, as the nascent civic engagement movement grew, teacher-researchers provided many useful descriptions of service-learning and community engagement projects embedded in coursework, and readers found these works very useful as sources of new ideas for their teaching. Today, over two decades later, scholars writing in this field must connect descriptions of innovative teaching approaches and student outcomes to a larger problem in educational research. As students, we learned to think of it this way: "What's at the top of the funnel?" (see Figure 1).

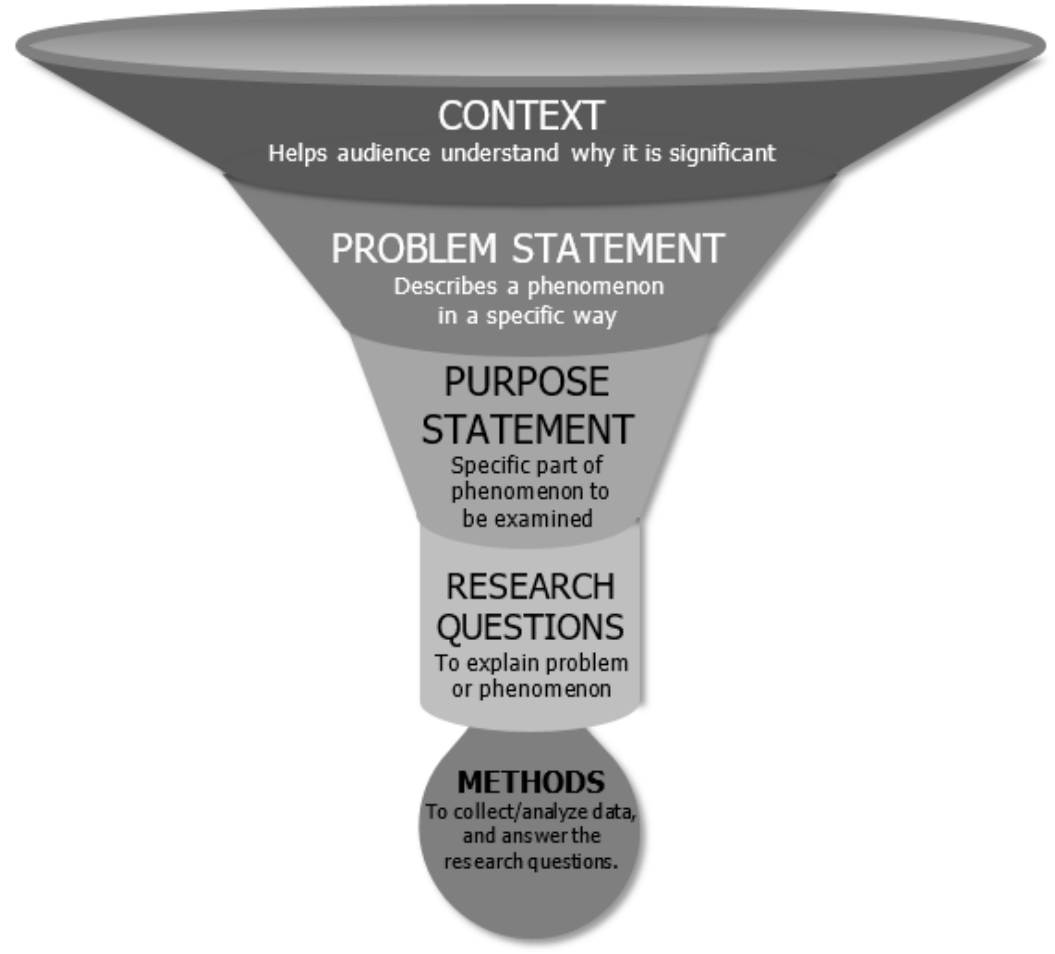

Figure 1. Contextualizing an educational research problem. Developed by Tami L. Moore, PhD, Melanie Wilderman, and Michelle Crew, Oklahoma State University, 2013. 
By articulating the specific relationships between student outcomes and global issues, scholars contextualize their use of experiential learning approaches - and the related student outcomes - vis a vis current issues facing society and, more specifically, the role that higher education faculty and community engagement professionals might play in addressing these issues by using service-learning as an active, experiential learning approach. The researcher states the research problem, followed by a statement of the purpose of the research, which is extended further by well-informed research questions. A foundation built on a thorough synthesis of literature and a robust contextual frame connecting the phenomenon to a current research problem informs methodological decisions affecting participant selection as well as data collection and analysis.

As section co-editors, we evaluated many intriguing submissions received for this volume of the journal based upon these criteria. Referring to the earlier funnel image helped us to determine what, if anything, was missing and allowed us to shape each article review and subsequent revisions in an intentional way. Reviewers and section editors continually found themselves asking one question: "What problem were the authors trying to solve by introducing service-learning into their classrooms?" In general, the authors of each of the five articles in this section respond to a common issue: the need for college graduates to acquire the personal, social, or vocational dispositions and skills associated with adult well-being and the capacity to respond to the demands that will be placed upon them by their societies and employers. In each instance, the instructor-or the institution as a whole - saw servicelearning or civic engagement as a possible approach for providing students opportunities to develop the necessary skills and attitudes. In the manuscripts included here, the authors provide a nuanced and evocative reading of their empirical findings, which may in turn prove useful in changing individual and institutional practices regarding the preparation of graduates for their diverse roles in society. We encourage authors of future submissions to use a similar approach for framing service-learning or civic engagement activities in the context of the larger problem of improving student outcomes.

\section{References}

Astin, A., Astin, H., \& Lindholm, J. (2011). Cultivating the spirit: How college can enhance students' inner lives. San Francisco, CA: Jossey-Bass.

Chickering, A. W. (1964). Dimensions of independence. Journal of Experimental Education, 32(3), 313316.

Chickering, A.W., \& Reisser, L. (1993). Education and identity. San Francisco, CA: Jossey-Bass Inc.

Perry, L., \& O’Steen, B. (2015). Student outcomes, K-20. International Journal of Research on ServiceLearning and Community Engagement, 3(1).

Werder, K. P., \& Strand, K. (2011). Measuring student outcomes: An assessment of service-learning in the Public Relations Campaigns course. Public Relations Review, 37, 478-484.

Winne, P. H., \& Hadwin, A. F. (1998). Studying as self-regulated engagement in learning. In D. Hacker, J. Dunlosky, \& A. Graesser (Eds.), Metacognition in educational theory and practice (pp. 277-304). Hillsdale, NJ: Lawrence Erlbaum. 
